\title{
The sympathetic response to euglycaemic hyperinsulinaemia
}

\section{Evidence from microelectrode nerve recordings in healthy subjects}

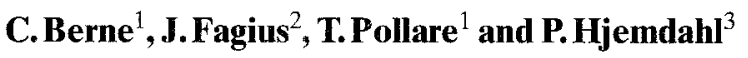 \\ ${ }^{1}$ Department of Internal Medicine, University Hospital, Uppsala, \\ ${ }^{2}$ Departments of Neurology and Clinical Neurophysiology, Uppsala, \\ ${ }^{3}$ Department of Clinical Pharmacology, Karolinska Hospital, Stockholm, Sweden
}

\begin{abstract}
Summary. Sympathetic nervous system activation by insulin has been suggested as a mechanism explaining the association between insulin resistance and hypertension. We further examined the effect of insulin by direct microneurographic muscle and skin nerve sympathetic activity recordings during euglycaemic insulin clamps in healthy subjects. The mean plasma insulin level was elevated from $5.3 \pm 0.7$ to $92.2 \pm 2.2 \mathrm{mU} / \mathrm{l}$ in seven subjects during a $90-\mathrm{min}$ one-step clamp. In six other subjects plasma insulin was further raised from $85.7 \pm 4.0 \mathrm{mU} / 1$ to $747 \pm 53 \mathrm{mU} / \mathrm{l}$ between 45-90 min (two-step clamp). Four of the latter subjects received a sham clamp with $\mathrm{NaCl}$ infusions only on a second recording session. At the low dose of insulin muscle nerve sympathetic activity increased from a resting level of $22.7 \pm 5.0$ bursts per min to $27.7 \pm 5.0$ bursts per min at $15 \mathrm{~min}$ $(p<0.05)$. The increases in muscle nerve sympathetic activity were significant $(p<0.001$; ANOVA) throughout insulin
\end{abstract}

infusion, with a slight further increase (from $29.2 \pm 1.6$ to $32.3 \pm 1.9$ bursts per min) at the supraphysiological insulin concentration. During sham clamps muscle nerve sympathetic activity did not increase. Both insulin clamps induced minor, but significant, increases in forearm venous plasma noradrenaline concentrations. Skin nerve sympathetic activity $(n=3)$ did not change during insulin infusions. Heart rate increased slightly but significantly $(p<0.005)$, during the insulin clamps. Blood pressure was not notably affected. In conclusion, hyperinsulinaemia was associated with increased vasoconstrictor nerve activity to skeletal muscle and with no change of sympathetic outflow to skin.

Key words: Sympathetic nervous system, catecholamines, insulin, blood pressure, glucose metabolism, hypertension, insulin resistance.
Insulin resistance and compensatory hyperinsulinaemia are frequently found with essential hypertension $[1,2]$. These associations have suggested that insulin is involved in the pathogenesis of hypertension. Among mechanisms which may play a causative role for the blood pressure elevation is the ability of insulin to stimulate renal sodium retention [3], affect transmembrane ionic fluxes [4] and to stimulate the activity of the sympathetic nervous system [5]. Acute studies have suggested that euglycaemic elevation of plasma insulin increases sympathetic nervous system activity $[6,7]$. These studies relied on measurements of forearm venous plasma noradrenaline concentrations, which represent a crude assessment of activity in the sympathetic nervous system [8]. However, the sympathetic nervous system is complex and is composed of many functionally different subdivisions, which are not necessarily activated simultaneously [9].

With microneurography baroreflex-governed vasoconstrictor nerve signals to the resistance vessels of the muscles can be assessed in human beings $[10,11]$. Using this method we have recently observed that glucose feeding is associated with a substantial enhancement of muscle nerve sympathetic activity (MSA) [12]. There was also a significant association between MSA and serum insulin concentrations after glucose ingestion, which suggested that insulin per se may, at least partly, mediate this response. Skin nerve sympathetic activity (SSA), involved in body temperature homeostasis and not under baroreceptor influence [11], was not changed by glucose intake [12].

Given this background we wanted to examine further if insulin alone might stimulate sympathetic outflow and whether such a stimulation, if detected, is a direct effect or a consequence of a baroreflex compensation of primary blood pressure changes. The study was carried out in healthy subjects, who were subjected to a euglycaemic insulin clamp, with concomitant recordings of MSA or SSA. Some of the present results have been presented in preliminary form [13]. During the preparation of this manuscript a similar study of MSA has been published [14]. 


\section{Subjects and methods}

Subjects. Sixteen non-obese, mean body mass index 21.8 (18.8$24.6) \mathrm{kg} / \mathrm{m}^{2}$, healthy volunteers (10 men and 6 women) aged $22-44$ (mean 29) years participated in the studies after giving their informed consent. The study was approved by the Human Ethics Committee of the Medical Faculty of Uppsala University. In the subjects altogether 20 microneurography registrations were performed.

Euglycaemic insulin clamp. The clamp was carried out according to DeFronzo [15] and has recently been described in detail [16]. After an initial infusion of a logarithmically falling priming dose of insulin given over $10 \mathrm{~min}$, the constant insulin infusion rate was $56 \mathrm{mU} \cdot \mathrm{m}^{-2} \cdot \mathrm{min}^{-1}$ (Actrapid Human; Novo Nordisk, Bagsvaerd, Denmark). This infusion rate was maintained for $90 \mathrm{~min}$ in ten experiments (seven recordings of MSA and three of SSA). In another six two-step clamps with MSA recordings only, the infusion rate was increased from 56 to $312 \mathrm{mU} \cdot \mathrm{m}^{-2} \cdot \mathrm{min}^{-1}$ between 45 and $90 \mathrm{~min}$. In four subjects, who had previously been subjected to the two-step insulin clamp, we performed sham clamps with MSA recordings, whereby the insulin and glucose infusions were substituted by $0.9 \%$ $\mathrm{NaCl}$. The rate of $\mathrm{NaCl}$ infusion was adjusted to exactly the same flow rate as in the preceding insulin clamp in the same subject and the blood sampling procedure was identical. The subjects were not informed of this substitution. In two further subjects in whom sham clamps were planned, the attempts to identify sympathetic nerve activity failed on the second occasion.

The target level for plasma glucose during the clamp was slightly above the fasting level, since it was important to avoid hypoglycaemia, which would have increased MSA and SSA $[17,18]$. The plasma glucose threshold for MSA increase is less than $4.0 \mathrm{mmol} / \mathrm{l}$, which was not reached during any of the clamps. The mean coefficient of variation for blood glucose in the euglycaemic clamps was $6.6 \%$.

Blood analyses. Plasma glucose was measured with a glucose oxidase method using a Beckman 2 glucose analyzer (Beckman Instruments Inc., Palo Alto, Calif., USA). Serum insulin was measured by radioimmunoassay (PhadeSeph; Pharmacia Fine Chemicals, Uppsala, Sweden). Haematocrit was measured by the Department of Clinical Chemistry (model S-plus Coulter counter; Coulter Electronics, Hialeah, Fla., USA). Blood for catecholamine analysis was collected in ice-chilled $10 \mathrm{ml}$ Vacutainer tubes containing $0.2 \mathrm{ml}$ of a solution of EGTA $(0.25 \mathrm{~mol} / \mathrm{l})$ and glutathione $(0.20 \mathrm{~mol} / \mathrm{l})$. The plasma catecholamine concentrations were measured by high-performance cation exchange liquid chromatography with electrochemical detection. The method is well validated and has inter- and intra-assay coefficients of variation of $2-3 \%$ in the nanomolar range [19]. The analyses were performed without knowledge of the results from the nerve recordings.

Nerve recordings. An insulated tungsten microelectrode with an uninsulated tip of about $5 \mu \mathrm{m}$ diameter was inserted through the skin at the right fibular head into the underlying peroneal nerve. A low impedance reference electrode was placed subcutaneously $2 \mathrm{~cm}$ away. The nerve was localized by means of electrical stimuli delivered through the recording electrode. An electrode position within a muscle nerve fascicle was identified by muscle twitches without concomitant skin paraesthesiae following electrical stimuli, and by afferent muscle spindle and tendon organ activity elicited by stretching or tapping the appropriate muscle. Correspondingly, a recording position within a skin nerve fascicle was defined when electrical stimuli evoked skin paraesthesiae without any twitches, and gentle touch within the skin area subserved by the nerve elicited mechanoreceptor afferent activity.

When a muscle or skin nerve fascicle was found, minute adjustments of the electrode position were made until the characteristic multi-unit bursts of MSA or SSA, respectively, were encountered. The criteria for the sympathetic origin of the signal recorded have been summarized previously [11]. Only the peroneal nerve was ex- plored, but this nerve is representative of the overall outflow of MSA and SSA to glabrous skin areas in all four extremities [11].

Minor discomfort may be experienced by the subject during the search for a recording position, but once this is found nothing is felt during continued recording. Transient slight paraesthesiae in the innervation zone of the nerve may occur a few days after the experiment. This was reported by one subject at follow-up by letter.

The nerve signal was amplified in two steps, with a total gain of $50,000 \mathrm{x}$, and fed through a $700-2000 \mathrm{~Hz}$ band pass filter and an amplitude discriminator for optimal signal-to-noise ratio. A resistancecapacitance integrating network with time constant $0.1 \mathrm{~s}$ delivered a mean voltage neurogram, which was used for display and analysis of the nerve activity.

Electrocardiograms (ECG) were recorded by chest surface electrodes.

All recorded signals were displayed on a storage oscilloscope and the nerve signal was also fed through a loudspeaker. The signals were stored on tape (FM tape recorder; Sangamo Weston-Schlumberger, Sarasota, Fla., USA) for subsequent analysis.

Blood pressure was measured at 3-min intervals by an automatic blood pressure recorder with a cuff applied to the right upper arm (EME 3200; EME Ltd, Brighton, Sussex, UK).

\section{General procedure}

The subjects came to hospital after an overnight fast and were asked to refrain from smoking in the morning. Two indwelling teflon catheters (Venflon; Viggo, Helsingborg, Sweden) for infusions and blood sampling were inserted. One was placed in an antecubital vein of the right arm and used for infusion and the other was placed in an antegrade position in a vein on the dorsum of the left hand for blood sampling. The hand was warmed by an electrical blanket-type heater.

When a suitable nerve recording electrode position was found (probing time 2-50 min), sympathetic activity, ECG and blood pressure were recorded during a resting period of about $20 \mathrm{~min}$. After this control period the euglycaemic insulin clamp was started by giving the priming dose of insulin. The subjects were instructed to relax during the entire experiment. During recordings of SSA the response to mental arithmetic (rapid serial subtraction of two-figure numbers) was tested at regular intervals throughout the experiment in order to check the recording site, since SSA (in contrast to MSA) is very sensitive to mental stress $[11,12]$.

\section{Analysis procedure}

The mean voltage neurogram and ECG were recorded on paper, $2.5 \mathrm{~mm} / \mathrm{s}$, with an ink-jet recorder (Mingograph; Siemens-Elema, Stockholm, Sweden). Bursts of MSA, time-locked in the cardiac rhythm, were counted during 6-min periods: at $-15,0,15,30,45,60$, 75 and $90 \mathrm{~min}$ in relation to the start of insulin infusion. For each subject the outflow of MSA was expressed as bursts per min for the period in question. Heart rate was obtained from the same paper display.

The burst amplitude in the mean voltage neurogram, reflecting the strength of individual bursts of MSA, cannot be compared between different recordings, since it is critically dependent on the intraneural electrode recording position. With an unchanged electrode position within a given recording, however, burst amplitude can be compared between different parts of the recording. Therefore, to further assess the change in MSA during the experiment, mean burst amplitude for the period of initial rest, at 45 min of insulin infusion, and at $90 \mathrm{~min}$ in subjects who were exposed to two levels of plasma insulin, was calculated as the mean of 50 consecutive bursts during that period for each subject. An unchanged electrode position throughout the experiment, being the prerequisite for this assessment, was achieved in five subjects undergoing the one-step insulin clamp and in five receiving the two-step clamp. (A change in electrode position is easily detected by the experienced microneurographer by a change in the recorded baseline and by a different 

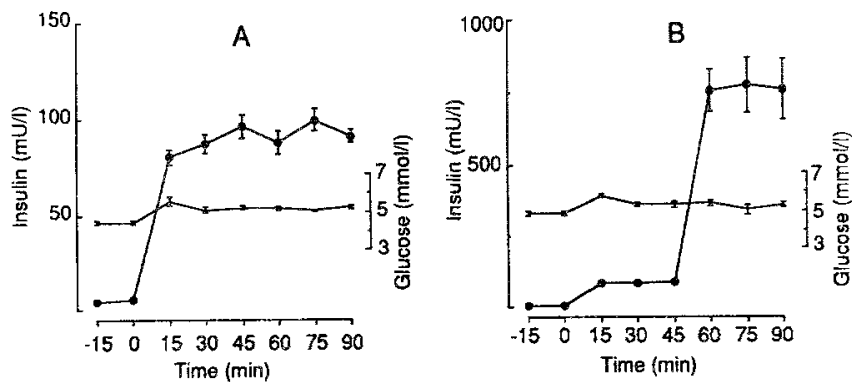

Fig. 1A, B. Plasma insulin and blood glucose levels during the euglycaemic insulin clamps with one $(\mathbf{A})$ and two (B) insulin infusion rates $\left(56\right.$ and $\left.312 \mathrm{mU} \cdot \mathrm{m}^{-2} \cdot \mathrm{min}^{-1}\right)$

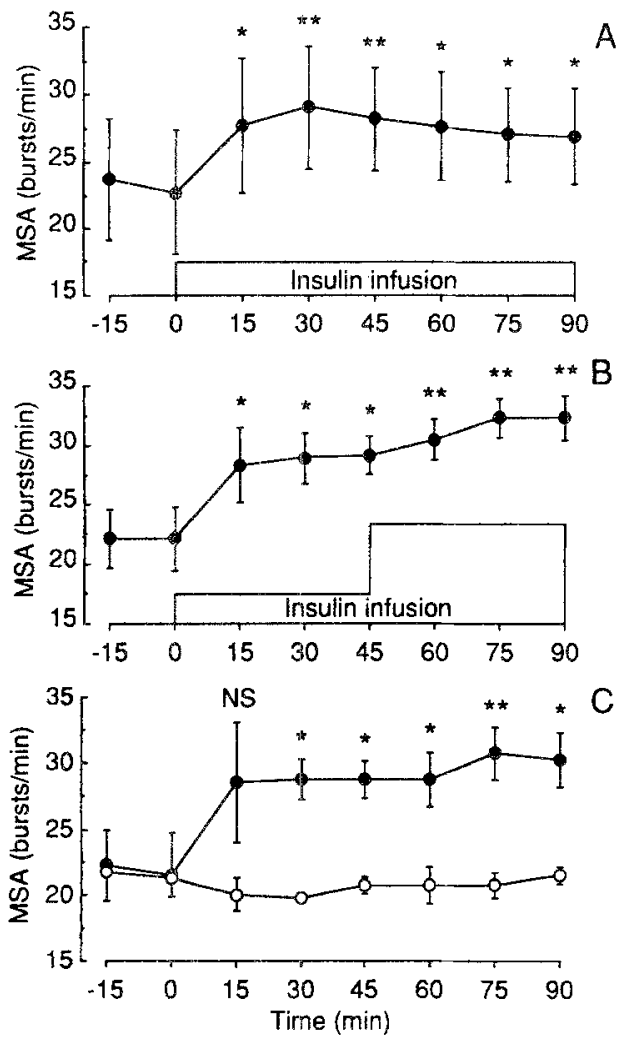

Fig. 2A-C. Muscle nerve sympathetic activity (MSA) expressed as number of bursts per min during the course of the one-step (A) and two-step (B) euglycaemic insulin clamps and the mean of four experiments with the two-step clamp (O) in comparison with sham clamps (O) with $0.9 \% \mathrm{NaCl}$ infusion in the same four subjects $(\mathbf{C})$. ${ }^{*} p<0.05 ;{ }^{* *} p<0.01$ compared to $0 \mathrm{~min}$

sound from the loudspeaker. The amplitudes were measured on a digitizing board (Hipad; Houston Instruments, Austin, Tex., USA) connected to a computer (Digital MicroVAX II; Digital Equipment, Maynard, Mass., USA) and were expressed in arbitrary units.

\section{Statistical analysis}

Recordings of SSA were analysed by inspection only, since it was obvious that no change was induced by insulin infusion. Blood pressure was calculated as the mean of three consecutive individual measurements during each period of analysis.

Results are expressed as mean \pm SEM. For statistical evaluation analysis of variance (ANOVA) with Dunnett's $t$-test for multiple comparisons, or Student's $t$-test for paired and unpaired observations were applied.

\section{Results}

\section{Euglycaemic insulin clamp}

All subjects were normoglycaemic at rest with fasting glucose concentrations of $4.8 \pm 0.1 \mathrm{mmol} / \mathrm{l}$ and basal plasma insulin concentrations of $5.3 \pm 0.7 \mathrm{mU} / \mathrm{l}$. The one-step clamp, with a constant insulin infusion rate during MSA recordings, resulted in a mean plasma insulin level of $92.2 \pm 2.2 \mathrm{mU} / 1$ (15-90 $\mathrm{min}$ ) (Fig.1 A). During the twostep clamp the mean insulin level was $85.7 \pm 4.0 \mathrm{mU} / \mathrm{h}$ during the low-dose infusion and $747 \pm 53 \mathrm{mU} / 1$ during the high-dose infusion (Fig.1B). During the sham experiments plasma insulin remained at the fasting level of $7.6 \mathrm{mU} / 1$ (range $6.5-8.7 \mathrm{mU} / 1$ ).

During the one-step clamp whole body glucose uptake was $7.5 \pm 1.8 \mathrm{mg} \cdot \mathrm{kg}^{-1} \cdot \mathrm{min}^{-1}$ between 0 and $45 \mathrm{~min}$ and $9.3 \pm 2.0 \mathrm{mg} \cdot \mathrm{kg}^{-1} \cdot \mathrm{min}^{-1}$ between 45 and $90 \mathrm{~min}$.

During the two-step clamp the glucose uptake was $7.2 \pm 0.9 \mathrm{mg} \cdot \mathrm{kg}^{-1} \cdot \mathrm{min}^{-1}$ between 0 and $45 \mathrm{~min}$ and $13.3 \pm 1.7 \mathrm{mg} \cdot \mathrm{kg}^{-1} \cdot \mathrm{min}^{-1}$ between 45 and $90 \mathrm{~min}$.

\section{Muscle nerve sympathetic activity (MSA)}

The time courses of MSA changes are depicted in Figure 2 .

During the one-step clamp (Fig. $2 \mathrm{~A}$ ), the elevation of plasma insulin was rapidly followed by an increase in MSA from a resting level of $22.7 \pm 5.0$ bursts per min to $27.7 \pm 5.0$ bursts per min (at $15 \mathrm{~min}$ ) with a maximum of $29.0 \pm 4.6$ bursts per min at $30 \mathrm{~min}(p<0.001$; ANOVA). The elevation of burst activity persisted throughout the experiment $(26.9 \pm 3.6$ bursts per min at $90 \mathrm{~min})$.
Control

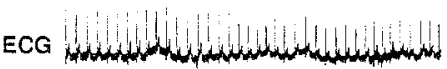

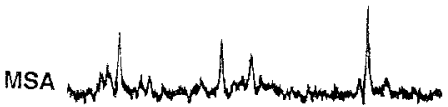

One-step eugiycaemic ciamp
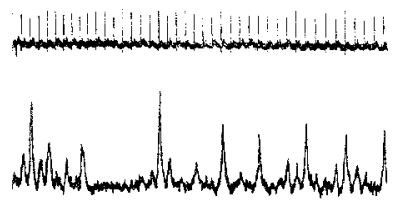

Control

ECG

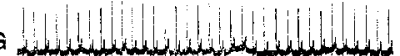

Sham experiment

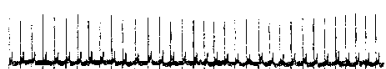

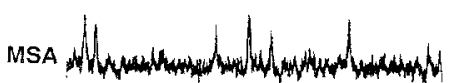

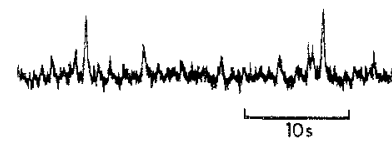

Fig. 3. A representative sample of muscle nerve sympathetic activity (MSA) original neurograms and electrocardiogram (ECG) recorded in one subject during resting conditions and after exposure either to the euglycaemic insulin clamp or to a sham infusion. Same time-scale in all panels 
Control

ECG

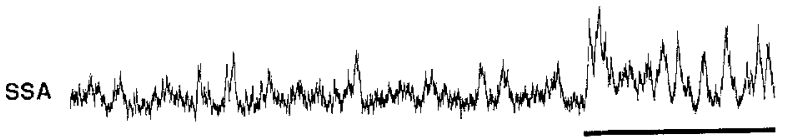

$\widetilde{105}$

One-step euglycaemic clamp

ECG

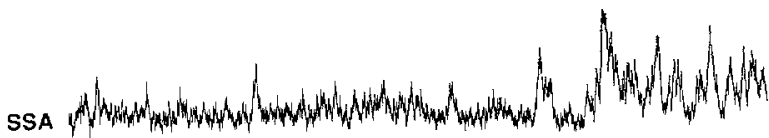

Fig.4. Samples from recordings of skin nerve sympathetic activity (SSA) in one subject initially at rest and after 30-min exposure to a one-step euglycaemic insulin clamp. Stress induced by mental arithmetic is indicated by a horizontal bar

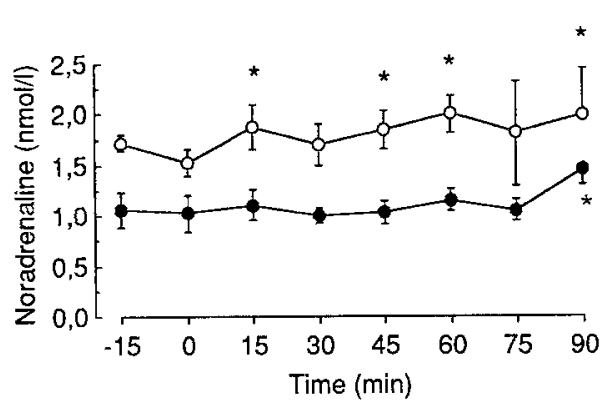

Fig.5. Mean plasma noradrenaline concentrations during the onestep (O) and two-step (๑) euglycaemic insulin clamps. ${ }^{*} p<0.05$ compared to $0 \mathrm{~min}$

When the insulin levels were elevated in two steps (Fig. 2B), MSA increased from $22.1 \pm 2.7$ bursts per min to $29.2 \pm 1.6$ bursts per min at the lower level. The further nine-fold increase of steady-state plasma insulin after 45 min was accompanied by a minor further enhancement of MSA to $32.3 \pm 1.9$ bursts per min at $90 \mathrm{~min}(p<0.0001$; ANOVA).

In the four subjects who also received sham clamps, MSA remained at the resting level throughout the experiment when $0.9 \% \mathrm{NaCl}$ was infused (Fig. $2 \mathrm{C}$ ).

Mean burst amplitude increased by $18 \%$ from the initial period of rest to $45 \mathrm{~min}$ after start of the low-dose insulin infusion $(n=10)$. At the high insulin level a further $20 \%$ increase in mean burst amplitude occurred $(n=5)$.

In Figure 3 the original neurograms are shown from recordings in one subject exposed to a one-step clamp and a sham experiment.

\section{Skin nerve sympathetic activity (SSA)}

We also performed three experiments in which SSA was identified and followed throughout the course of an eugly- caemic insulin clamp. SSA was found not to respond to the elevated insulin level. A typical experiment is shown in Figure 4. To ascertain that the low level of activity was real and not due to loss of the position of the recording electrode, the subjects were asked to perform mental arithmetic during the experiment. It was found that this procedure elicited a brisk response of SSA throughout the experiment (Fig.4) in each of the three subjects, indicating that the low-grade activity was not artifactual.

\section{Plasma noradrenaline}

Both clamps were followed by minor, but significant increases in forearm venous plasma noradrenaline concentrations (significance levels for the changes over time were for the one-step clamp, $p<0.05$ and for the two-step clamp, $p<0.01$; ANOVA) (Fig. 5). In the sham clamp plasma noradrenaline remained stable, with no significant changes over time $(1.39 \pm 0.51 \mathrm{nmol} / \mathrm{l}$ at $0 \mathrm{~min}$ and $1.65 \pm 0.41 \mathrm{nmol} / \mathrm{l}$ at $90 \mathrm{~min})$.

\section{Cardiovascular changes}

Blood pressure was affected slightly by the insulin clamps. During the one-step clamp there were no significant changes in systolic or diastolic blood pressure (Fig. 6 A). The high insulin infusion rate was accompanied by a minor but significant late elevation of systolic blood pressure at $90 \mathrm{~min}$ (from 127.7 to $133.5 \mathrm{~mm} \mathrm{Hg}$ ). During the sham clamp there were no significant changes in blood pressure (at $0 \mathrm{~min}, 127 / 70 \mathrm{~mm} \mathrm{Hg}$ and $90 \mathrm{~min}$, $131 / 77 \mathrm{~mm} \mathrm{Hg}$ ).

Both euglycaemic insulin clamps elevated the heart rate slightly but significantly (one-step, $p<0.0001$ and

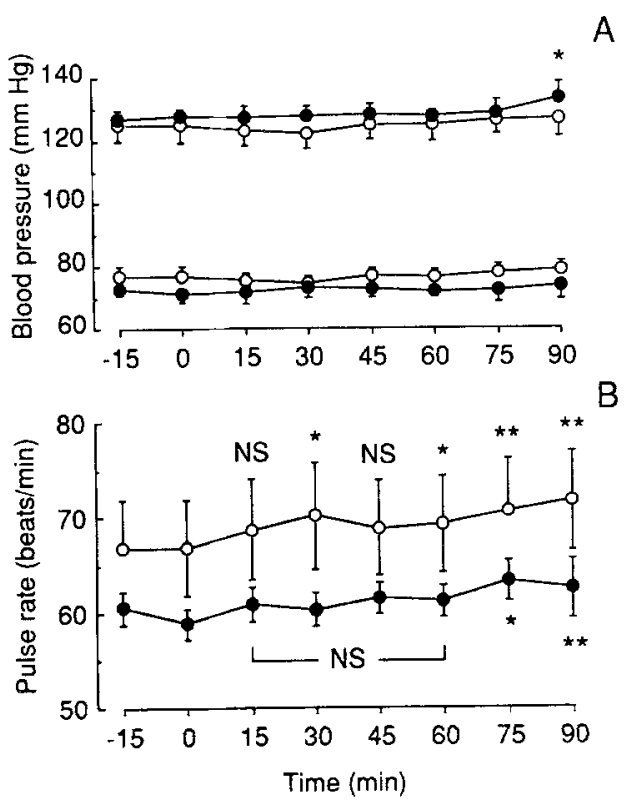

Fig. 6A,B. Courses of supine systolic and diastolic blood pressure (A) and pulse rate (B) throughout the one-step $(O)$ and two-step (O) euglycaemic insulin clamps. $* p<0.05, * * p<0.01$ compared to $0 \mathrm{~min}$ 
two-step, $p<0.005$; ANOVA) (Fig. 6B). The increase was slightly larger at the end of the high-dose insulin infusions as compared to at the end of the one-step clamp (8.9 vs $6.8 \%, \mathrm{NS})$. During the sham clamp the mean heart rate at each time point was $53-56$ beats per min throughout the experiment.

During the one-step clamp haematocrit decreased from $38.0 \pm 1.4 \%$ to $37.6 \pm 1.2 \%$ after $90 \mathrm{~min}(p<0.01$; ANOVA). The corresponding values for the two-step clamp were $42.0 \pm 1.0 \%$ and $40.8 \pm 1.1 \% \quad(p<0.001$; ANOVA), respectively.

\section{Discussion}

The present study has demonstrated that an elevation of the plasma insulin under euglycaemic conditions increases the impulse traffic in sympathetic nerve fascicles conducting vasoconstrictor signals to the resistance vessels of skeletal muscle in healthy humans.

The plasma insulin concentration attained during the low dose of insulin was in the high physiological range, whereas the high dose of insulin resulted in a supraphysiological plasma insulin concentration. Most of the increase in MSA was, however, already observed at the low dose, indicating that the reaction occurs at physiological plasma insulin concentrations.

The oral administration of D-glucose was recently shown to invoke a strong and sustained increase in MSA, which was correlated with the rise in plasma insulin [12]. Under these experimental conditions, factors such as splanchnic vasodilation and gastric distension may have contributed to the sympathetic stimulation. Such factors are excluded by the use of the euglycaemic insulin clamp technique and the present increase in MSA should be an isolated effect of hyperinsulinaemia. The increase in MSA was less prominent in the present study than that observed following the oral glucose load [12] - maximal increase was $17.4 \pm 4.4$ bursts per min after oral glucose intake and $6.3 \pm 0.4$ bursts per min in the seven subjects given the low dose of insulin in the present study $(p=0.025, t$-test of non-paired observations). This difference indicates that a direct effect of insulin is only one mechanism underlying the response to oral glucose.

There were two major reasons to perform sham clamps in order to substantiate the observation of a response of MSA to insulin. First, even if MSA is weakly sensitive to environmental stress [20] such an effect caused by the experimental situation had to be excluded. Secondly, MSA may also increase in response to unloading of volume receptors [21]. Even if blood sampling was reasonably wellbalanced by the glucose administered, minor plasma volume changes might have occurred and stimulated MSA. The observed minor decrease in haematocrit is most likely related to the glucose and $\mathrm{NaCl}$ infusions. This change indicates volume expansion, which would have attenuated rather than enhanced the MSA response [11, 12]. It seems safe to conclude that the major cause of the increase in MSA observed in this study was hyperinsulinaemia.

Hyperinsulinaemic euglycaemic clamps in humans have not given consistent changes of circulating catechol- amines. Elevation of plasma insulin to a mean steadystate level of $46 \mathrm{mU} / \mathrm{l}$ [22] or 100-200 mU/l failed to elevate plasma catecholamines [23, 24], whereas other investigations have found minor but significant elevations of plasma noradrenaline at plasma insulin concentrations ranging from a level corresponding to postprandial hyperinsulinaemia in normal and insulin-resistant subjects, i.e. less than $100 \mathrm{mU} / 1$ [25] to supraphysiological levels [6, 7, 26]. The occasional failure to observe increases in plasma noradrenaline may be methodological, as moderate hyperinsulinaemia is apparently a weak sympathetic stimulus.

The MSA recordings, however, provide direct evidence that hyperinsulinaemia stimulates the part of the sympathetic nervous system that conveys vasoconstrictor impulses to the muscle vessels. In a recent study of MSA during euglycaemic hyperinsulinaemia [14] an increase similar to the present one was observed, with concomitant vasodilation in the arm and without major changes in blood pressure. This latter study [14] also displayed a moderate but significant increase in plasma noradrenaline more pronounced than that in the present study. Under resting conditions and some manoeuvres affecting blood pressure and its regulation, MSA has been shown to correlate to plasma noradrenaline levels [27-29]. The relationship between MSA and noradrenaline is best displayed when the two variables are observed in the same region, but even so it is weakened during complex manoeuvres such as mental stress [20]. Also during adrenaline infusions MSA increases more than plasma noradrenaline [30]. Thus, the unequivocal increase of MSA in response to insulin is not incompatible with the small elevations of plasma noradrenaline. It is notable that hyperinsulinaemia failed to affect the outflow of skin nerve sympathetic impulses, thus emphasizing that the sympathetic nervous system is complex with subdivisions not necessarily activated together $[8,11,20]$. The absence of an SSA response is also compatible with the recent observation that cutaneous blood flow was unaffected by the elevated insulin concentrations during a euglycaemic clamp [31].

The insulin-induced increase in MSA may be related to either direct stimulation of the central nervous system or a baroreflex-mediated response to circulatory changes.

Insulin has been shown to cause vasodilation [32] and attenuates noradrenaline- and angiotensin II- induced vasoconstriction in vitro [33]. Studies with the euglycaemic clamp have yielded conflicting results in humans. A number of studies have reported an increased blood flow in skeletal muscles of the limbs [14, 26, 34-36], whereas others have reported unchanged blood flow [37-39]. Recently, a dose-response relationship between the plasma insulin concentration and enhanced leg blood flow has been established and insulin resistance was associated with a blunted vasodilatory response [36].

A vascular site of action for insulin is also substantiated by a number of studies which have shown that insulin produces hypotension in patients with severe autonomic failure, whether caused by diabetic autonomic neuropathy [40] or primary dysautonomia [41-43]. Thus, in clinical states in which noradrenaline release is likely to be seriously impaired or absent, insulin may induce a precipi- 
tous fall in blood pressure, independent of its hypoglycaemic action. This suggests that the MSA response is of importance for the maintenance of blood pressure.

The quoted vascular effects of insulin suggest that the MSA response might be reflexogenic, since MSA is under baroreceptor inhibitory control and is increased by intermittent decrements of diastolic blood pressure or persistent reductions of central venous pressures [11]. If reflexogenic, the MSA response should be expected to be preceded by a reduction in blood pressure. Neither in the present study nor after glucose ingestion [12], have we observed any fall in blood pressure indicating that the increase in MSA might be caused by unloading of baroceptors. Blood pressure was measured only intermittently (3-min intervals) and minor fluctuations of the blood pressure may have escaped detection, but one should not expect such fluctuations to evoke a sustained increase in MSA. The recently published related study [14] also did not suggest a fall in blood pressure to be a major determinant of the MSA response.

Thus, a direct action of insulin on central sympathetic motor neurons may underlie the increase in MSA, if so eliciting a resetting of the baroreflex working level. Very few experimental data have been produced to support a central mechanism of action. Administration of insulin directly into the carotid artery raises blood pressure in dogs [44]. Insulin receptors are widely distributed in the brain, and are primarily located on neurons $[45,46]$. Insulin has also been shown to alter the neuronal firing rate [47] and interfere with catecholamine uptake in cultured neurons [48], but the exact role for insulin-induced central neuromodulation of the sympathetic nervous system activity is largely unknown.

Whether stimulation of sympathetic nervous system activity by insulin plays a role in the development of hypertension in insulin resistant subjects is still an open question. Neither the present study nor that by Anderson et al. [14] displayed any convincing evidence for a rise in blood pressure during experimental hyperinsulinaemia. Furthermore, long-term elevation of insulin (from 8.5 to $35-40 \mathrm{mU} / \mathrm{l}$ ) in mongrel dogs failed to increase plasma catecholamines or blood pressure [49].

Acknowledgements. Financial support was received from the Swedish Medical Research Council (nos 5930 and 7468), the Selander Fund for Medical Research, the Research Fund of the Swedish Diabetes Association, the Nordic Insulin Foundation, the Ernfors Fund for Diabetes Research, Hoechst Foundation for Diabetes Research and Novo Nordisk Pharma AB.

\section{References}

1. Ferrannini E, Buzzigli G, Bonadonna R et al. (1987) Insulin resistance in essential hypertension. N Engl J Med 317:350-357

2. Pollare T, Lithell H, Berne C (1990) Insulin resistance is a characteristic feature of primary hypertension independent of obesity. Metabolism 39: 167-174

3. DeFronzo RA, Goldberg M, Agus ZS (1976) The effects of glucose and insulin on renal electrolyte transport. J Clin Invest 58: $83-90$

4. Clausen T, Everts ME (1989) Regulation of the $\mathrm{Na}^{+} \mathrm{K}^{+}$pump in skeletal muscle. Kidney Int 35: 1-13
5. Sowers JR, Whitfield LA, Catania RA et al. (1982) Role of the sympathetic nervous system in blood pressure maintenance in obesity. J Clin Endocr Metab 54: 1181-1186

6. Rowe JW, Young JB, Minaker KL, Stevens AL, Pallotta J, Landsberg L (1981) Effect of insulin and glucose infusions on sympathetic nervous system activity in normal man. Diabetes 30 : 219-255

7. O'Hare JA, Minaker KL, Meneilly GS, Rowe JW, Pallotta JA, Young JB (1989) Effect of insulin on plasma norepinephrine and 3,4 dihydroxyphenylalanine in obese men. Metabolism 38: 322329

8. Folkow B, DiBona GF, Hjemdahl P, Thorén PH, Wallin BG (1983) Measurements of plasma norepinephrine concentrations in human primary hypertension. A word of caution on their applicability for assessing neurogenic contributions. Hypertension $5: 399-403$

9. Hjemdahl P (1990) Physiology of the autonomic nervous system as related to cardiovascular function: implications for stress research. In: Byrne DG, Rosenman RH (eds) Anxiety and the heart. Hemisphere, Nẹw York, pp 95-157

10. Hagbarth KE, Vallbo $\AA$ (1968) Pulse and respiratory grouping of sympathetic nerve impulses in human muscle nerves. Acta Physiol Scand 74: 96-108

11. Wallin BG, Fagius J (1988) Peripheral sympathetic neural activity in conscious humans. Ann Rev Physiol 50: 565-756

12. Berne C, Fagius J, Niklasson F (1989) Sympathetic response to oral carbohydrate administration. Evidence from microelectrode nerve recordings. J Clin Invest 84: 1403-1409

13. Berne C, Pollare T, Fagius J (1989) The sympathetic outflow in vasoconstrictor nerve fascicles to muscle is increased during euglycaemic hyperinsulinaemia. Diabetologia 32: 465 A (Abstract)

14. Anderson EA, Hoffmann RP, Balon TW, Sinkey CA, Mark AL (1991) Hyperinsulinaemia produces both sympathetic neural activation and vasodilation in normal human beings. J Clin Invest $87: 2246-2252$

15. DeFronzo RA, Tobin JD, Andres R (1979) Glucose clamp technique: a method for quantifying insulin secretion and resistance. Am J Physiol 237: 214-223

16. Pollare T, Lithell $\mathrm{H}$, Selinius I, Berne C (1988) Application of prazosin is associated with an increase of insulin sensitivity in obese patients with hypertension. Diabetologia 31: 415420

17. Fagius J, Niklasson F, Berne C (1986) Sympathetic outflow in human muscle nerves increases during hypoglycemia. Diabetes 35: 1124-1129

18. Berne C, Fagius J (1986) Skin nerve sympathetic activity during insulin-induced hypoglycaemia. Diabetologia 29: $855-860$

19. Hjemdahl P (1987) Catecholamine measurements by high-performance liquid chromatography with electrochemical detection. Methods Enzymol 142: 521-534

20. Hjemdahl P, Fagius J, Freyschuss U et al. (1989) Muscle sympathetic activity and norepinephrine release during mental challenge in humans. Am J Physiol 257: E654-E664

21. Sundlöf $G$, Wallin BG (1978) Effect of lower body negative pressure on human muscle nerve sympathetic activity. J Physiol 278: 525-532

22. Mauricio-Leguizamo G, Heineman L, Scharf RE, Berger M (1989) Effect of 8 hours of hyperinsulinaemia on haemostatic parameters in healthy man. Diabetologia 32: 606-610

23. Schwartz NS, Clutter WE, Shah SD, Cryer PE (1987) Glycemic thresholds for activation of glucose counterregulatory systems are higher than the thresholds for symptoms. J Clin Invest 79: 777-781

24. Boyle PJ, Schwartz NS, Shah SD, Clutter WE, Cryer PE (1988) Plasma glucose concentrations at the onset of hypoglycemic symptoms in patients with poorly controlled diabetes and nondiabetics. New Engl J Med 318: 1487-1492

25. Hilsted J, Christensen NJ, Larsen S (1989) Effect of catecholamines and insulin on plasma volume and intravascular mass of albumin in man. Clin Sci 77: 149-155 
26. Scott AR, Bennett T, MacDonald IA (1988) Effects of hyperinsulinaemia on the cardiovascular responses to graded hypovolemia in normal and diabetic subjects. Clin Sci 75: 85-92

27. Wallin BG, Mörlin C, Hjemdahl P (1987) Muscle sympathetic activity and venous plasma noradrenaline concentrations during static exercise in normotensive and hypertensive subjects. Acta Physiol Scand 129: 489-497

28. Eckberg DL, Rea RF, Andersson OK et al. (1988) Baroreflex modulation of sympathetic activity and neurotransmittors in humans. Acta Physiol Scand 133: 221-231

29. Victor RG, Seals DR, Mark AL (1987) Differential control of heart rate and sympathetic nerve activity during dynamic exercise. Insights from direct intraneural recordings in humans. J Clin Invest 79: 508-516

30. Persson B, Andersson OK, Hjemdahl P, Wysocki M, Agerwall S, Wallin BG (1989) Adrenaline infusion in man increases muscle sympathetic nerve activity and noradrenaline overflow to plasma. J Hypertension 7: 747-756

31. Åman J, Berne C, Ewald U, Tuvemo T (1992) Cutaneous blood flow during a hypoglycaemic clamp in insulin-dependent diabetic patients and healthy subjects. Clin Sci 82: 615-618

32. Liang CS, Doherty JU, Faillace R et al. (1982) Insulin infusion in conscious dogs. Effects on systemic and coronary hemodynamics, regional blood flows, and plasma catecholamines. J Clin Invest 69: 1321-1336

33. Yagi S, Takata S, Kiyokawa $\mathrm{H}$ et al. (1988) Effects of insulin on vasoconstrictive responses to norepinephrine and angiotensin II in rabbit femoral artery and vein. Diabetes 37: 1064-1067

34. Creager MA, Liang C-S, Coffman JD (1985) Beta adrenergicmediated vasodilator response to insulin in the human forearm. $J$ Pharmacol Exp Therapeut 235: 709-714

35. Richter EA, Mikines KJ, Galbo H, Kiens B (1989) Effects of exercise on insulin action in human skeletal muscle. J Appl Physiol 66: 876-885

36. Laakso M, Edelman SV, Brechtel G, Baron AD (1990) Decreased effect of insulin to stimulate skeletal muscle blood flow in obese man. J Clin Invest 85: 1844-1852

37. James DE, Burleigh KM, Storlien LH, Bennett SP, Kraegen EW (1986) Heterogeneity of insulin action in muscle: influence of blood flow. Am J Physiol 251: E422-E430

38. Jackson RA, Hamling JB, Blix PM et al. (1986) The influence of graded hyperglycemia with and without physiological hyperinsulinaemia on forearm glucose uptake and other metabolic responses in man. J Clin Endocr Metab 63: 594-604
39. Yki-Järvinen H, Young AA, Lamkin C, Foley JE (1987) Kinetics of glucose disposal in whole body and across the forearm. J Clin Invest 79: 1713-1719

40. Page MM, Watkins PJ (1976) Provocation of postural hypotension by insulin in diabetic autonomic neuropathy. Diabetes 25: 90-95

41. Mathias CJ, Da Costa DF, Fosbraey P, Christensen NJ, Bannister $R$ (1987) Hypotensive and sedative effects of insulin in autonomic failure. Br Med J 295: 161-163

42. Bannister R, Da Costa RF, Kooner JS, MacDonald IA, Mathias CJ (1987) Insulin-induced hypotension in autonomic failure during euglycaemia in man. J Physiol (London) 382: 36P

43. Brown RT, Polinsky RJ, Baucom CE (1989) Euglycemic insulininduced hypotension in autonomic failure. Clin Neuropharm 12: 227-231

44. Pereda SA, Eckstein JW, Abboud FM (1962) Cardiovascular responses to insulin in the absence of hypoglycemia. Am J Physiol 202: $249-252$

45. Heidenreich KA (1991) Insulin in the brain. What is its role. TEM 2: 9-12

46. Hill JM, Lesniak MA, Pert CB, Roth J (1986) Autoradiographic localization of insulin receptors in rat brain: prominence in olfactory and limbic areas. Neuroscience 17:1127-1131

47. Sakaguchi T, Takahashi M, Bray GA (1988) Diurnal changes in sympathetic activity. Relation to food intake and to insulin injected into the ventromedial or suprachiasmatic nucleus. J Clin Invest 82: 282-286

48. Boyd FT, Clarke DW, Raizada MK (1985) Insulin receptors and insulin modulation of norepinephrine uptake in neuronal cultures from rat brain. J Biol Chem 260: 15880-15884

49. Hall JE, Brands MW, Kivlighn SD, Mizelle HL, Hildebrandt DA, Gaillard CA (1990) Chronic hyperinsulinaemia and blood pressure. Interaction with catecholamines. Hypertension 15: $519-527$

Received: 3 December 1991

and in final revised form: 19 May 1992

Dr. C. Berne

Department of Internal Medicine

University Hospital

S-751 85 Uppsala

Sweden 